\title{
An Analysis of Highest Diurnal Precipitations Changes and Their Related to Annual Precipitations in Iran
}

\author{
Mehdi Heshmati Jadid ${ }^{1}$, Ghasem Azizi ${ }^{2}$, Hasan Zolfaghari ${ }^{3}$, Mehdi Fashi ${ }^{4} \&$ Sayied Dana Alizadeh $^{5}$ \\ ${ }^{1}$ Azad University of Kermanshah, Iran \\ 2 Department of Geography, University of Tehran, Iran \\ ${ }^{3}$ Department of Geography, University of Razi, Iran \\ ${ }^{4}$ Razi University, Iran \\ ${ }^{5}$ Kharazmi University, Tehran, Iran \\ Correspondence: Mehdi Heshmati Jadid, Azad University of Kermanshah, Iran. Tel: 98-918-938-8259. E-mail: \\ mehdiheshmati64@yahoo.com
}

Received: November 13, 2012 Accepted: December 31, 2012 Online Published: March 6, 2013

doi:10.5539/esr.v2n2p40 URL: http://dx.doi.org/10.5539/esr.v2n2p40

\begin{abstract}
In this paper, in order to study of the highest daily precipitations of daily precipitations data in 46 synoptic and climatologic stations that almost covered all part of Iran have been got from the national weather organization and have been used after the extraction of necessary data for a 30-year period from 1976 to 2005. In concerning of data analysis, necessary statistical analyses like data homogeneity test, normality test, correlation test, simple and multiple regressions, variance analysis, Friedman's non parametric test and classification cluster analysis have been used. The results showed that the average of the highest precipitations in all the studied stations during the statistical period of the research, except in two stations of Boushahr and Khoy, don't have any significant difference. Investigation of the changes of the highest annual precipitations in the statistical period in each of these stations showed that these changes are significant in Sanandaj station and in the other stations no significant change is observed. The results also proved that there is a positive and significant relation between the highest daily precipitation and annual precipitation in all the stations which means increase in the annual precipitation the highest daily precipitation of stations growth. Finally climatic classification of the stations displays 5 layers in terms of the proportion from highest daily rain to annual rain in the country.
\end{abstract}

Keywords: heavy daily precipitations, spatial-temporal variations, classification, regionalization, Iran

\section{Introduction}

The studies have done over the world show an overall increase in the occurrence rains in the recent decades (Peralta-Hernandez et al., 2009). Although the global warming might lead to the change in the amount of annual precipitations in some area, the distribution and frequencies precipitation might converted heavy and short term rainfalls. In other words warming can cause enhancing the short and heavy precipitation and consequently floods and the damage related to them increases (Mas'oudian, 2000). The average of annual precipitation in Iran is about $250 \mathrm{~mm}$ that is one third of the average world precipitation. Based on the results of many climatic classifications, Iran known as a dry and semi-dry climate region. Low amount of rainfalls, high variability in each year is another significant characteristic of Iran's climate. Beside the above characteristics, spatial distribution of rainfalls has not been similar and decreases from west to east and from north to south (Zolfaghari, 2000). In addition to heterogeneous spatial distribution, huge temporal fluctuations are also seen; in a way that the coefficient of variation in many stations goes over 40 percent. So, spatial and temporal abnormalities of precipitation, huge changes in intensity of precipitations and difference in the kind of precipitation are the most common characteristics of precipitations in Iran (Babai \& Faraj, 2001). Investigation of heavy precipitations in dry and semi-dry regions like Iran where a large part of the annual precipitation may happen during only a few days has of greater importance. Therefore, the ratio of diurnal precipitation to annual is a criterion for recognizing the intensity of diurnal precipitations. The high ratio shows that the occurrence of heavy and temporary is significant and low ratio shows moderate rainfalls and higher frequency of rainy days (Jahanbakhsh \& Zolfaghari, 2000). This study aims at showing whether global warming or the change in climates affect the extreme precepitations (highest 
diurnal rainings)or their correlation with the annual rainings and how much in which places these they have changed.

Various studies have been done in this field in the world and specially in Iran also related issues to this have been done among which some items are mentioned here. In a study by Karl and Knight (1998) on periodic trends, frequency and intensity of precipitations in a long-term period (1910-1995) in US show although in 20 century the average precipitations have not changed a lot, extreme precipitations particularly in East and Eastern South has had an upward trend. Ramasamy and Kevin (1998) have studied days of heavy rainfall and number of dry periods in Australia from 1910 to 1990 to control floods in watershed management and urban design projects. Yigong et al. (2002) in a research titled" diurnal precipitations of the semi-dry land in the north of China from 1956 to 2000 concluded that rainy days have decreased to 8 days until 1990 and although the extreme diurnal precipitations don't show any significant trend, the average of daily maximum precipitations has decreased from 1979-1990". In another study by Harpham and Wilby (2005) about predicting the occurrence and amount of heavy diurnal rainfalls in some small zones in England, 3 statistical models have been compared in different places. The Models were used, include Radial Basis Function (RBF), Artificial Neural Network (ANN) and Multi-Layer Perception (MLP). Test of models with independent data during (1979 to 1993) has showed that ANN models, with higher precision, have forecasted $80 \%$ of the rainfalls. Fujibe et al. (2005) have done a study associated with the positive trend in heavy precipitations in Japan based on four - hour data for a period of more than 100 years (1898-2003). The result which is a positive trend in heavy 4-hour, daily and hourly rainfalls and a decrease in the light precipitations for all seasons and regions. Robinic and Ozanic (2006) have analyzed the correlation of heavy diurnal and annual rainfalls in the mountainous area of Jersky Kutar and coastal region of Croatia in the statistical period from 1950 to 1983 and have found that there is a strong dependence between the annual precipitations and 20-100 mm diurnal rainfalls but there is not a strong correlation between heavy rainfalls of more than $100 \mathrm{~mm}$ and annual rainfalls. Nastos and Zerefos (2007) who have studied extreme diurnal rainfalls in Aznes of Greece from 19891 to 2004 have observed important changes in the amount of diurnal precipitations in different extreme thresholds like 10,20,30 and 50 particularly a negative trend in the number of wet days specially after 1968 and a positive trend in extreme amounts of daily rainfalls. Lana et al. (1995) have studied the highest amount of daily precipitations in Catalonia in Spain. Nishiyama et al. (2007) have studied real synoptic patterns creating heavy precipitations in the rainy season of Japan.

In Iran also heavy rainfalls have been of interest to some researchers. Investigation of highest amount of diurnal precipitations from northwest to southwest of Iran has been done by Jahanbakhsh and Zolfaghari, (2000) and in their study data of highest amount of daily precipitations in a 10-year period from 1987 to 1996 have been chosen and analyzed. Their results show that spatial distribution of the ratio of diurnal to annual rainfall is not homogeneous and there is a direct relationship between diurnal and annual precipitations. Alijani (2002) investigated the highest level of daily rainfalls during the statistical period (1961-1985) in Iran and has found that temporal distribution of precipitations in the north is more congruent than in the south and the condition in the south is similar to an irregular desert diet. Among all regions of Iran, diurnal rainfalls of Anarak to Ghaen is less than others and shows that distance from humidity sources has caused this condition. He also has shown the spatial-temporal distribution of heavy rainfalls in Iran. Ghanbarpour and et al., (2000) have calculated the ratio of short-term rainfalls (15 minutes to 12 hours) to the highest daily rainfalls and have illustrated the changes in amount of the ratio, also regional difference of these amounts in terms of isolines on the map of Iran. Ghanbarpour and Talouri (2003) have studied and compared temporal distribution of 24hour-rains and patterns of the type of temporal distribution. So, the result of their study display heterogeneity in the patterns of rainfalls. Rahimzadeh (2005) has performed a study titled investigation of changes of extreme amounts of participations in Iran. The authors has investigated some indices like more than $100 \mathrm{~mm}$ rainy days, daily intensity index, highest 5-day rainfall and days with total rainfall of more than $95^{\text {th }}$ percentile in the statistical period (1951-2003) for selected stations in Iran. Radmanesh et al. (2006) aiming at determining the relationship between rainfalls more than 24 hours and diurnal precipitations, have studied these characteristics for different probabilities. Mohammadi and Taghavi (2005) have investigated the trend of extreme temperature and precipitation in Tehran that associated with the phenomenon of changing climates and results have shown that extreme indices of precipitation have a slight downward trend. Also Faraji Sabokbar and Azizi (2006) have done a spatial study of rainfalls using interpolation methods in Kashafroud basin and showed that among interpolation methods, methods of Tin and Krijing have better and more realistic results. Asgari and Rahimzadeh (2006) have studied the variability of the precipitations during the last decades in Iran using T-Student parametric and Man-Kendall and Spirman's non-parametric methods in the form of qualitative analysis of the trend. Their results showed that the country had experienced both positive and negative trends in the total annual precipitations of synoptic stations. Iran-Nejad et al. (2007) in a research called the portion of frequency and intensity variations of the diurnal precipitations, during a period from 
1960 to 2001 for 38 selected stations, they have found that the trend of annual total precipitations in 10 stations and the number of rainy days in 21 stations is significant (at $90 \%$ ). Most of the stations in the area of west and northwest had a negative annual precipitation trend and most of the stations in the south and central area of Iran had positive trends. Precipitation trend in winter has been similar to annual trend. In spring it has been negative and in autumn positive trend in most of the stations. Hajam et al. (2008) have analyzed the process of variations in annual and seasonal precipitations in some selected stations in the central area of Iran using non-parametric methods. They used Man-Kendall and Sen's stimator slope tests for the analysis of the trends of seasonal and annual rainfalls. Their result showed considering the inefficiency of the number and strength of the significant series with trend in comparison with the series of lacking trend, cannot attribute any particular trend to the seasonal and annual precipitations of the area under study. In this regard also Razi'i and Azizi (2008) have investigated spatial distribution of seasonal and annual rainfalls in the west of Iran. They have calculated and used Precipitation Concentration index (PCI) to show spatial precipitation differences. Their results showed that precipitation rhythm in northern parts of the study area with maximum rainfalls in spring is different from central and southern parts which have their highest precipitation in winter and it was also revealed that the distribution of rainfalls follows latitudes and it is more regular in northern part of the region than the southern part. Lashgari (1996) has studied heavy precipitation in southwest of Iran. He has concluded that these precipitations are the result of strengthen and intensify the activity of Sudan low pressure centre and Red sea convergence zone that turning them into a dynamic and thermodynamic system. Heidari (2002) has done synoptic analysis of the monthly heaviest rainfalls of the west of Iran. Mofidi (2004) in a paper titled synoptic climatology of Red sea originate heavy precipitation in Middle East, announces that formation of primary Red sea convergence zone is the result of mutual effect of tropospheric and Topographic characteristics. Khaleghi Zavareh and Marzban Dashtabadi (2006) with the goal of synoptic investigation of diurnal rainfalls of more than $50 \mathrm{~mm}$ in Kohgilouyeh Buyer Ahmad province in the statistical period of 1994 to 2003, about 34 systems which have caused such rainfalls in the above period have been studied. The results of their research show that these waves influenced by the penetration of low pressure centers of Mediterranean and eastern through of the Red sea which are formed and created heavy rains in the studied area.

\section{Data and Methods}

Daily precipitation data of 46 synoptic (Figure 1) and climatology stations for a 30-year period from 1976 to 2005 have been got from the meteorology organization of Iran so the data of the highest diurnal and annual precipitations were extracted by using these data.

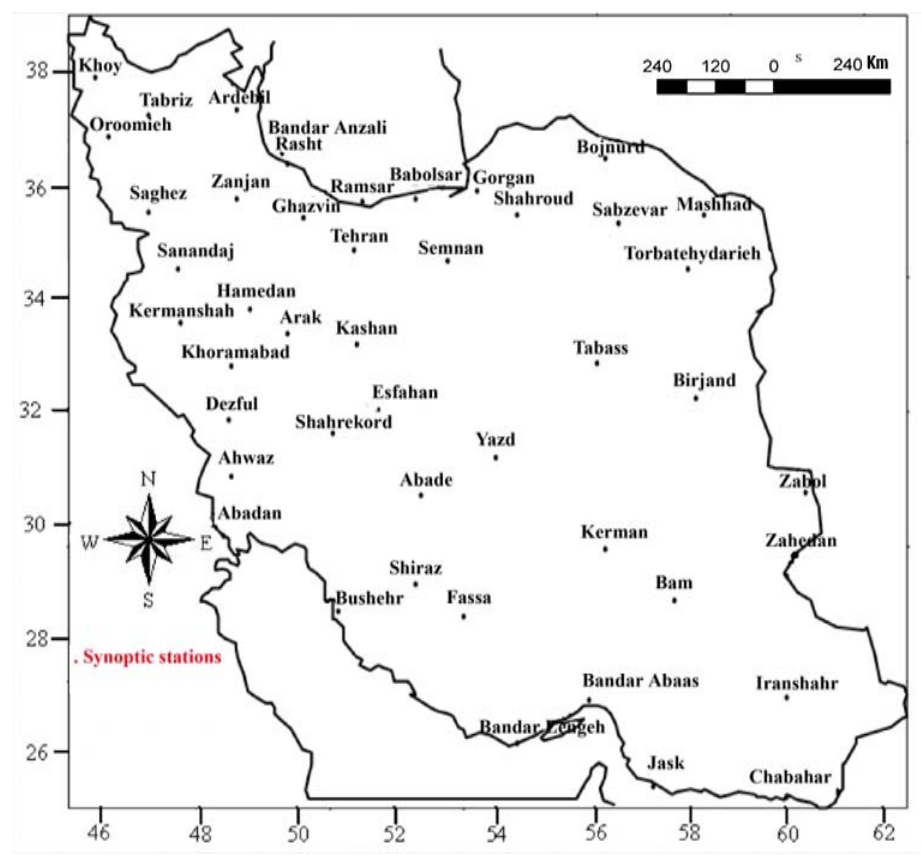

Figure 1. Distribution of the studied stations in Iran

Stations which had the most statistics during a period of 30 years and also had a proper distribution in all geographical latitudes and heights were selected to reach acceptable results. In figure1 the geographical position of the stations has been shown. 
For proving the homogeneity of the research data non-graphical Run test method was used.

Investigating the variables, randomness of the data was studied with the error probability of 0.05 and their homogeneity was assured. For fitting of the distribution of the data with normal distribution, Kolmogrov-Smirnov, which is one of the non-parametric methods of Goodness-of-Fit Test, has been used. Data of maximum daily precipitation in all the studied stations in this test had a significant level of over 0.05 . Also the normality of the proportion of maximum precipitations to annual precipitations of the stations using the second root of these proportions during three decades was done separately. Also for calculating the proportion of maximum diurnal rainfalls to annual precipitations in different parts of the country without meteorological stations, regression bi-variable methods were confirmed.

For investigating the changes in the amounts of highest daily precipitations during the period in the studied areas, in each of the studied stations, information of the highest diurnal precipitations of the 30-year period turned into 3 decades and Pearson's correlation coefficient was used to identify correlations among the data of these decades. For stations in the decades of which there was no correlation, using one way variance analysis test (ANOVA), existence of differences between the three decades was examined. After assuring of the difference between the averages of highest diurnal precipitations among the three decades, for distinguishing the average variability of the decades from each other, the LSD (least significant difference) has been used. Because in this study significance level of variances homogeneity test is over 0.05 , using LSD is justifiable. For comparing the average of the decades which were correlated Friedman's nonparametric test was used. This test is applied for comparing the averages of some correlated communities. In this test if the significance level is less than 0.05 difference is significant. Otherwise there is not any difference among the average of the decades.

For investigating the quality of the relation of diurnal and annual precipitations of each of the studied stations and also significance test of this relation, because of the good potential of the method, Pierson's correlation coefficient was utilized. For assuring the significance of the difference between the averages of the proportion of maximum diurnal to annual precipitations in the studied decades for each station ANOVA was used. Apart from determining the difference between averages, we might like to know which of the averages are different. The condition to use ANOVA is the homogeneity of the variances. At last for stations with meaningful difference Post Hoc test was done. In the end as part of the goals of this research, for identifying the condition of highest diurnal precipitations and their proportion to annual precipitations in Iran, regionalization of highest diurnal precipitations and the proportion of maximum daily rainfalls to annual rainfalls which have been done using the Cluster analysis and Ward method are also mentioned.

\section{Results}

\subsection{Temporal Changes of Maximum Daily Precipitations}

In order to study process of changes in highest daily precipitations during the period of study, variance analysis (ANOVA) has been used, because the condition of using of this test is statistical independence of the variables, first of all data of the highest diurnal precipitations in the 30-year statistical period from 1976 to 2005 in each station was turned into three decades (1976 to 1985), (1986 to 1995) and (1996 to 2005) and among them correlation test was performed by using Pierson's correlation coefficient. The results of correlation test in all stations showed that except in stations of Iranshahr, Kashan, Khoram Abad, Mashhad, Rasht and Saqez, there is no significant correlation among decades. This means that the three decades are independent from each other and changes of each decade do not have any significant effect on the other decades. In the mentioned stations in the level of $0.05\left(^{*}\right)$ and only in Zahedan station in level of $0.01(* *)$ there is significant correlation among decades, the results of which are shown in Table 1.

Table 1. Correlation coefficients test among decades in correlated stations

\begin{tabular}{ccccc}
\hline Raw & Station & $\begin{array}{c}\text { First decade with second } \\
\text { decade }\end{array}$ & $\begin{array}{c}\text { First decade with third } \\
\text { decade }\end{array}$ & $\begin{array}{c}\text { Second decade with third } \\
\text { decade }\end{array}$ \\
\hline 1 & Kashan & -0.294 & -0.119 & $0.664^{*}$ \\
2 & Koram abad & 0.124 & 0.081 & $0.634^{*}$ \\
3 & Mashhad & $0.729^{*}$ & 0.421 & 0.409 \\
4 & Rasht & $-0.652^{*}$ & 0.145 & -0.107 \\
6 & Saghez & -0.064 & $0.729^{*}$ & -0.043 \\
7 & Zahedan & $0.849^{* *}$ & 0.096 & -0.086 \\
8 & Iranshahr & 0.125 & $-0.727^{*}$ & -0.061 \\
\hline
\end{tabular}


In the next phase in stations where there was not any correlation among decades, using one way ANOVA, the existence of differences among three decades was investigated. Along the process of test, homogeneity test which is a necessity to it was performed on the data and the results are demonstrated in Table 2.

Table 2. Significance level of one way ANOVA and variances homogeneity test for stations lacking correlation coefficient among decades

\begin{tabular}{|c|c|c|c|}
\hline Raw & Station & Test of On way ANOVA (Significance level) & Test of Homogeneity of Variances (Significance level) \\
\hline 1 & Abadan & 0.533 & 0.813 \\
\hline 2 & Abade & 0.614 & 0.087 \\
\hline 3 & Ahvaz & 0.077 & 0.079 \\
\hline 4 & Arak & 0.474 & 0.006 \\
\hline 5 & Ardebil & 0.854 & 0.860 \\
\hline 6 & Babolsar & 0.970 & 0.412 \\
\hline 7 & Bam & 0.325 & 0.826 \\
\hline 8 & Bandar abass & 0.744 & 0.229 \\
\hline 9 & Bandar anzali & 0.357 & 0.196 \\
\hline 10 & Bandar lengeh & 0.425 & 0.876 \\
\hline 11 & Birjand & 0.553 & 0.584 \\
\hline 12 & Bojnurd & 0.954 & 0.813 \\
\hline$\underline{13}$ & $\underline{\text { Bushehr }}$ & $\underline{0.003}$ & $\underline{0.204}$ \\
\hline 14 & Chabahar & 0.934 & 0.843 \\
\hline 15 & Dezful & 0.165 & 0.233 \\
\hline 16 & Esfahan & 0.979 & 0.717 \\
\hline 17 & Fassa & 0.925 & 0.035 \\
\hline 18 & Ghazvin & 0.810 & 0.580 \\
\hline 19 & Gorgan & 0.947 & 0.554 \\
\hline 20 & Hamadan & 0.847 & 0.243 \\
\hline 21 & Jask & 0.162 & 0.067 \\
\hline 22 & Kerman & 0.679 & 0.324 \\
\hline 23 & Kermanshah & 0.062 & 0.005 \\
\hline$\underline{24}$ & $\underline{\text { Khoy }}$ & $\underline{0.030}$ & $\underline{0.146}$ \\
\hline 25 & Oroomieh & 0.116 & 0.815 \\
\hline 26 & Ramsar & 0.471 & 0.436 \\
\hline 27 & Sabzavar & 0.213 & 0.417 \\
\hline 28 & Sanandaj & 0.982 & 0.893 \\
\hline 29 & Semnan & 0.711 & 0.127 \\
\hline 30 & Shahrekord & 0.466 & 0.012 \\
\hline 31 & Shahrud & 0.530 & 0.988 \\
\hline 32 & Shiraz & 0.321 & 0.007 \\
\hline 33 & Tabass & 0.406 & 0.070 \\
\hline 34 & Tabriz & 0.128 & 0.021 \\
\hline 35 & Tehran & 0.534 & 0.754 \\
\hline 36 & Torbat Hydarieh & 0.940 & 0.473 \\
\hline 37 & Yazd & 0.058 & 0.063 \\
\hline 38 & Zabol & 0.278 & 0.378 \\
\hline 39 & Zanjan & 0.957 & 0.167 \\
\hline
\end{tabular}

One way ANOVA also, has determined the differences among the three decades. Results of this test displayed that except stations in Boushehr and Khoy, in other stations significance level is over 0.05. It means that the averages of the decades do not have any significant difference, so it implies that in these stations during the three studied decades; amounts of the maximum precipitations have not had a significant change. For detecting decades among 
which there are significant changes LSD has been used. According to the results of LSD in Boushehr between the first and third decade with significance level of 0.001 and between second and third decade with significance level of 0.007 among averages of the highest diurnal precipitations there is a significant difference. But between the first and second decade with significance level of 0.473 there is no significant difference between averages of highest daily precipitations. Also according to the results of LSD test which was done for Khoy station, between the first and second decade with significance level of 0.014 and between the first and third decade with significance level of 0.695 there is no significant difference between averages of the highest diurnal precipitations.

More than the mentioned statistical results for better showing the difference between the average of maximum diurnal precipitations of decades in Boushehr and Khoy stations graph method which has been shown in Figure 2 and 3 have also been used.

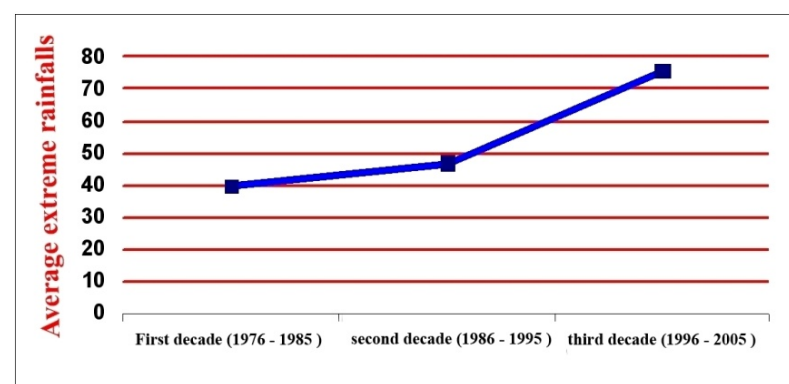

Figure 2. Variation of the average of highest precipitations during 3 decades in Boushehr station

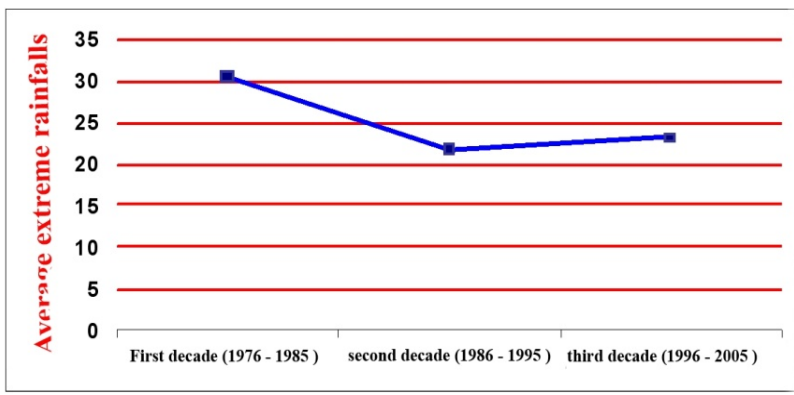

Figure 3. Variation of the average of highest precipitations during 3 decades in Khoy station

As can be seen in Figure 2 the average of highest daily precipitations during 3 decades in Boushehr station has an upward trend that as it is shown between second and third decades increase is more meaningful and significant. In Khoy station (Figure 3) also between the averages of maximum daily rainfalls from the first to second decade, we can observe a significant downward trend.

Also for the stations of Iranshahr, Kashan, Khoram Abad, Mashhad, Rasht and Saqez with significant correlation in the level of 0.05 among their decades and Zahedan in the level of 0.01 , for comparing the average of decades in these stations Friedman's non-parametric test has been used. Results of this test for the mentioned stations are brought in Table 3 .

Table 3. Results of Friedman test for correlated stations

\begin{tabular}{cccccc}
\hline Raw & Station & Significance level (sig) & Raw & Station & Significance level (sig) \\
\hline 1 & Iranshahr & 0.905 & 5 & Rasht & 0.905 \\
2 & Kashan & 0.209 & 6 & Saghez & 0.497 \\
3 & Khoram Abad & 0.497 & 7 & Zahedan & 0.191 \\
4 & Mashad & 0.285 & & & \\
\hline
\end{tabular}

As it can be observed in the results of Friedman test significance level in the results of this test for all the mentioned stations is over 0.05 , it demonstrates that among averages of highest daily precipitations during these 3 decades there is no significant difference. Therefore, in general according to statistical findings we can conclude that averages of the highest daily precipitations in all stations in Iran during the statistical period 1976 to 2005 except in two stations of Boushehr and Khoy have not had any significant difference. It means that amounts of highest daily precipitations in Iran do not follow a growing or falling trend and during this time they have been around approximately similar averages.

\subsection{The Relation between Maximum Daily and Annual Precipitation}

In order to study the relation between highest daily and annual precipitation, for each station correlation coefficient was separately calculated. The results of calcularions showed that except stations of Anzali, Sanandaj and Khoram Abad, in other stations there is a significant correlation coefficient between maximum daily and annual precipitations. Table 4 shows Pierson's correlation coefficient between maximum daily and annual precipitations. 
Table 4. Correlation coefficient between maximum daily and annual precipitations

\begin{tabular}{|c|c|c|c|c|c|c|c|c|}
\hline Raw & Station & $\begin{array}{l}\text { Correlation } \\
\text { Coefficients }\end{array}$ & Raw & Station & $\begin{array}{l}\text { Correlation } \\
\text { Coefficients }\end{array}$ & Raw & Station & $\begin{array}{l}\text { Correlation } \\
\text { Coefficients }\end{array}$ \\
\hline 1 & Abadan & $0.614 * *$ & 17 & Fassa & $0.618 * *$ & 33 & Saghez & $0.440 * *$ \\
\hline 2 & Abade & $0.762 * *$ & 18 & Ghazvin & $0.491 * *$ & 34 & Sanandaj & 0.222 \\
\hline 3 & Ahvaz & $0.517 * *$ & 19 & Gorgan & $0.472 * *$ & 35 & Semnan & $0.538 * *$ \\
\hline 4 & Arak & $0.374 *$ & 20 & Hamedan & $0.643 * *$ & 36 & Shahrekord & $0.548 * *$ \\
\hline 5 & Ardebil & $0.512 * *$ & 21 & Iranshahr & $0.628 * *$ & 37 & Shahrud & $0.674 * *$ \\
\hline 6 & Babolsar & $0.622 * *$ & 22 & Jask & $0.767 * *$ & 38 & Shiraz & $0.570 * *$ \\
\hline 7 & Bam & $0.647 * *$ & 23 & Kashan & $0.736 * *$ & 39 & Tabass & $0.551 * *$ \\
\hline 8 & Bandar abass & $0.630 * *$ & 24 & Keman & $0572 * *$ & 40 & Tabriz & $0.659 * *$ \\
\hline 9 & Bandar anzali & 0.338 & 25 & Kermanshah & $0.512 * *$ & 41 & Tehran & $0.561 * *$ \\
\hline 10 & Bandar lengeh & $0.765 * *$ & 26 & Khoram abad & 0.194 & 42 & Torbat hydarieh & $0.478 * *$ \\
\hline 11 & Birjand & $0.414 *$ & 27 & Khoy & $0.404 *$ & 43 & Yazd & $0.700 * *$ \\
\hline 12 & Bojnurd & $0.511 * *$ & 28 & Mashhad & $0.589 * *$ & 44 & Zabol & $0.797 * *$ \\
\hline 13 & Boshehr & $0.670 * *$ & 29 & Oroomieh & $0.541 * *$ & 45 & Zahedan & $0.537 * *$ \\
\hline 14 & Chabahar & $0.809 * *$ & 30 & Ramsar & $0.690 * *$ & 46 & Zanjan & $0.473 * *$ \\
\hline 15 & Dezful & $0.527 * *$ & 31 & Rasht & $0.399 * *$ & & & \\
\hline 16 & Esfahan & $0.595 * *$ & 32 & Sabzevar & $0.506^{* *}$ & & & \\
\hline
\end{tabular}

*Average variability is significant in the level of 0.05 .

**Average variability is significant in the level of 0.01 .

Then for each of the stations a linear regression was done between two variables of maximum daily and annual precipitations. The results of which showed that in the three stations of Anzali, Sanandaj and Khoram Abad independent variable of annual precipitation does not affect daily precipitation as a dependent variable, that means in these stations, despite the expectations, for the time being when there is much annual precipitation there is not necessarily heavy daily rainfalls. In other stations according to the regression tables in standardized coefficients (Beta) we can see that the effect of annual rainfalls is positive and significant, that means increase in annual precipitations causes increase in daily precipitations. In other words there is a direct relationship between their daily and annual maximum precipitations. Wherever annual rainfalls are higher, amount of maximum daily rainfalls is high too.

\subsection{Changes of the Proportion of Daily to Annual Precipitations}

At the beginning, for studying the differences in the proportion of highest daily precipitations to annual precipitations and for the ease of the job, the statistical period was divided into three separate decades (1976-1985), (1986-1995) and (1995-2005). Then for studying the changes in the amount of proportion of daily rainfalls to annual precipitations, variance analysis method was used. Because this method needs statistical independence among variables, this is the three studied decades, in the first place we should investigate this hypothesis. Therefore, the significance of correlation test among three decades was performed in different stations.

The results of this correlation show that except stations in Kermanshah, Abadan, Shahrood, Zabol and Ardabil, none of the stations had a significant correlation. This means the proportion of maximum daily precipitations to annual precipitations in three decades did not have any relationship to each other. Afterwards for determining the existence of significant difference between decades for stations in Kermanshah, Abadan, Shahrood, Zabol and Ardabil, because of significant correlation, Friedman's non-parametric test was used for studying the differences the results of which is the lack of significant difference between decades. This means that in three decades there is no difference regarding the proportion of maximum daily precipitations to annual rainfalls. Results of Friedman's non-parametric test have been presented in Table 5 .

For other stations because the correlations were not significant One way ANOVA was used. In this test, first of all the hypothesis of variance homogeneity was examined. The Results of this test shows that except stations in Arak, Khoram Abad, Khoy, Kashan, Ramsar and Torbate Heydarieh, in other stations hypothesis of variance homogeneity was confirmed that is determined with significant amounts of more than 0.05 . So this means that stations are homogeneous regarding the proportion of maximum daily precipitations to annual precipitations. Finally based on variance analysis, only in Sanandaj station difference between decades is significant in the level 
of 0.05. Also, this means in all stations excluding Sanandaj, in the three studied decades, amount of this proportion has not had a significant change. Regarding Sanandaj station, existence of a significant difference among three decades was examined and using a LSD test it was revealed that the proportion of highest daily precipitations to annual precipitations in the third decade has been the most.

Table 5. Results of Friedman's non-parametric test

\begin{tabular}{cccccc}
\hline Raw & Station & Significance level & Raw & Station & Significance level \\
\hline 1 & Kermanshah & 0.202 & 4 & Zabol & 0.061 \\
2 & Abadan & 0.273 & 5 & Ardebil & 0.905 \\
3 & Shahrud & 0.407 & & & \\
\hline
\end{tabular}

\subsection{Regionalization of the Proportion of Maximum Daily to Annual Precipitations}

In order to be able to show the condition of the highest daily precipitations and their proportion to annual precipitations during the statistical period in terms of location in a better way, the proportion of the highest daily precipitations to annual precipitations and absolute amounts (maximum) of highest daily precipitations have been classified to display their condition and amounts in this class better. For this reason, for clarifying the spatial pattern of distribution of the proportion of maximum daily precipitations to annual precipitations in Iran, Cluster analysis method was used. According to what Figure 4 shows in Iran we can identify 5 different regions with the proportion of maximum diurnal precipitations to annual precipitations.

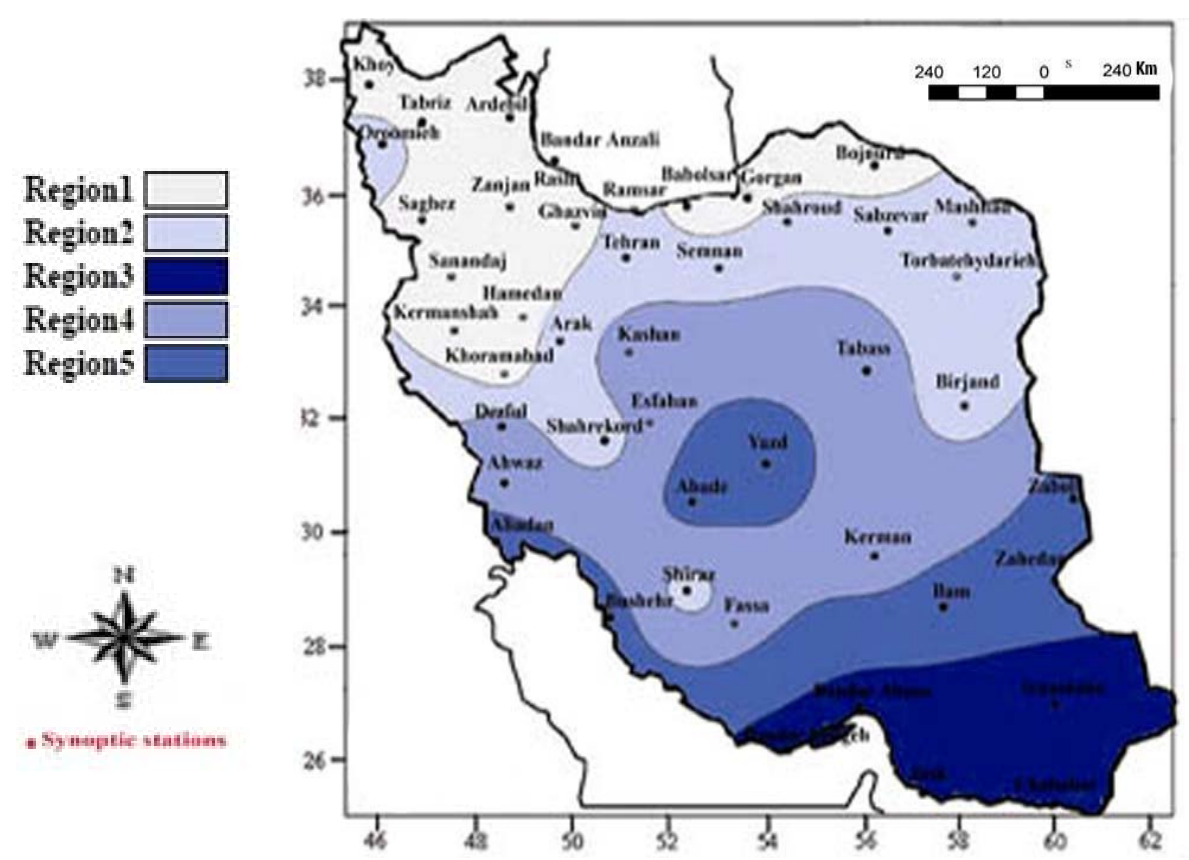

Figure 4. Regionalization of proportion of maximum daily to annual precipitations in Iran

Region 1: includes stations of Sanandaj, Zanjan, Ardabil, Gorgan, Saqez, Qazvin, Khoy, Tabriz, Babolsar, Kermanshah, Khoram Abad, Bojnourd, Hamedan, Anzali and Rasht. In total average of the proportion of highest daily to annual precipitations in the region is $8.2 \%$.The average of the annual precipitation and average of maximum daily precipitation are respectively 574.6 and $46.4 \mathrm{~mm}$. The Highest daily precipitation of the region was $240 \mathrm{~mm}$ in Anzali. In this station the average of the proportion of precipitation is 8\%. In 1978 highest daily precipitation was $86 \mathrm{~mm}$ that involves $18 \%$ of annual precipitations.

Region 2: includes stations of Tehran, Torbate Heydarieh, Arak, Ramsar, Shahre kord, Mashhad, Orumiyeh, Semnan, Shahrood, Birjan, Sabzevar and Shiraz. The average of proportion of the highest daily to annual precipitations in this region is $11.8 \%$. The average of annual precipitations $335.9 \mathrm{~mm}$ and the average of maximum 
daily precipitation is $40.5 \mathrm{~mm}$. The highest daily precipitation in the region was $340.2 \mathrm{~mm}$ in Ramsar. The average of proportion of the highest daily precipitations to annual ones in Sabzevar is 12\%.

Region 3: this region includes stations of Bandar Abas, Chabahar, Jask and Iranshar. The average of proportion of highest daily to annual precipitations in this region is $32 \%$. The average of the highest daily to annual precipitations in the whole region is $38.9 \mathrm{~mm}$. Also the average annual precipitations are $147.6 \mathrm{~mm}$. In 2001, about $72 \%$ of annual precipitations happened in one day that reveals the strong growing factor in proportion to other days in the region.

Region 4: stations of Fasa, Kerman, Ahvaz, Kashan, Tabas, Esfehan and Dezfoul are in this region. The average of the proportion of the highest daily to annual precipitations in this region is $16 \%$. The average of the highest daily precipitation $34.3 \mathrm{~mm}$ and annual precipitation is $213.4 \mathrm{~mm}$. The amount of changes in the proportion of the highest daily to annual rainfalls during the statistical period is little. Only in 1978 this amount has increased significantly to $40.9 \%$.

Region 5: the stations of Yazd, Zahedan, Babol, Abadan, Abadeh and Boushehr are in fifth region. 23.4\% of annual precipitations of this region happen in one day. The highest daily precipitation of the region, $144 \mathrm{~mm}$, happened in Boushehr. Average of the annual precipitations is $121 \mathrm{~mm}$. The changes of this proportion in Zahedan station are too many, in a way that in 1982 the amount of this proportion was $10.2 \%$ while it reached to $58.5 \%$ in 2004.

While the results show from north to south of the country, amount of the highest daily precipitations to annual precipitations increases, that is the least amount of proportion of daily to annual precipitations are seen in the north of the country and the most is observed in eastern south and south. This result somehow shows normality and regularity of precipitations in the north. While precipitations in the south are more sudden and irregular that is somehow a sign of higher frequency of rain systems in the north of the country. Classification of the proportion of highest daily to annual precipitations has proved this well too.

\subsection{Regionalization of Absolute (Maximum) of Highest Daily Precipitations}

As can be seen in Figure 5, the maximums of the highest daily precipitations are seen in the north of the country that its amount in stations of Ramsar gets to $340.2 \mathrm{~mm}$ and in another place as in Anzali gets to $240 \mathrm{~mm}$ and then in southern parts of the country (Persian Gulf coasts) the highest amount of it in Bandar Abas reaches $211 \mathrm{~mm}$. Of course, centers of daily maximums of over $100 \mathrm{~mm}$ are also seen in western part of the country. The least amount of the maximums also is seen in central and eastern regions. All of these indicate high humidity and rising factors in regions having the highest diurnal precipitations and lack of humidity in central and eastern regions.

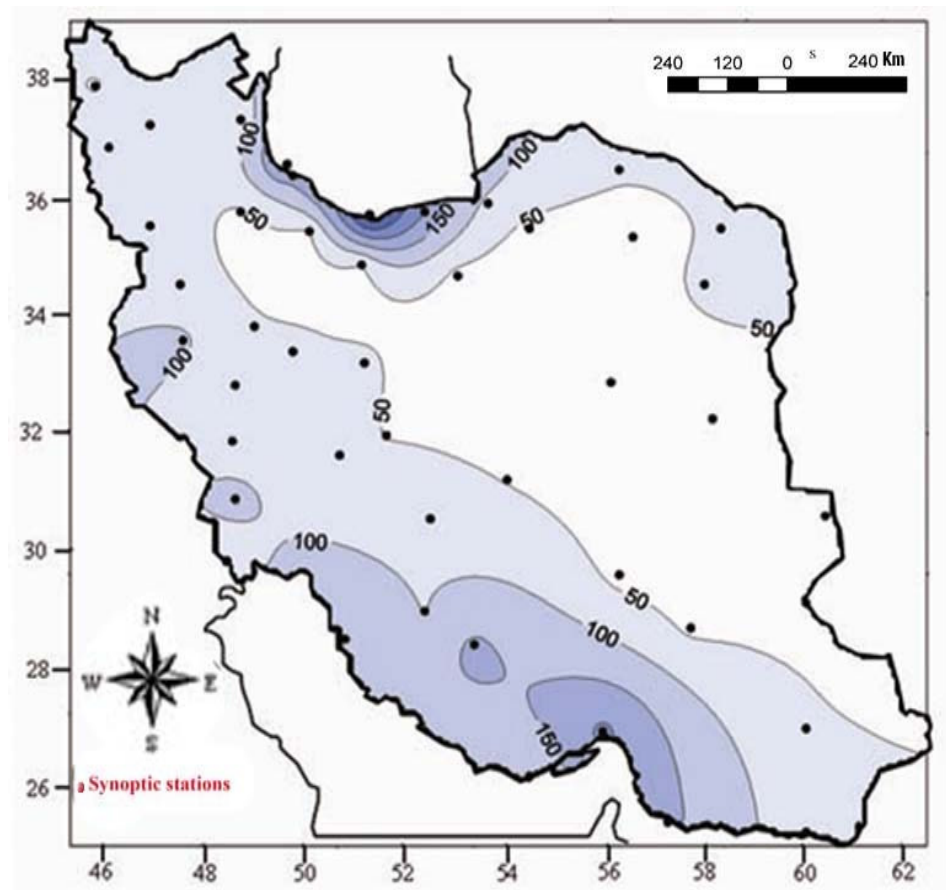

Figure 5. Distribution of absolute amounts of highest daily precipitation 


\section{Discussion and Conclusion}

Regarding to change in climates, different researches have been done or are being done in order to clarify the quality of this subject in terms of location and time. In this study we have tried to take a special look at the extreme amounts of precipitation. According to this attitude, the present paper has elaborated on the analysis of changes in the highest daily precipitations and their proportion to annual precipitations in Iran. We have tried to use different statistical methods that include; correlation, double and multiple regressions, variance analysis and Friedman's test for achieving the goals. Investigating temporal changes of highest daily precipitations during the statistical period of (1976-2005) and statistical tests showed that there is not a significant difference between the averages of the highest daily precipitation of the stations. This means during studied statistical period the highest daily precipitations in Iran did not have any significant change. Only in the station of Boushehr, a positive trend was observed that specially in the second and the third decade this increase is more meaningful and significant and the station of Khoy, with negative trend among the average of the highest daily precipitations from the first to the second decade there is a significant decade.

In order to investigate the relationship between the highest daily and the annual precipitations of the stations, for each of them correlation was calculated separately. The result of these correlations showed that except in stations of Anzali, Sanandaj and Khoram Abad, in other stations, there is significant correlation between the highest daily and annual precipitations. Then for each of the stations, a linear regression was performed between two variables of maximum daily and annual precipitation, the results of which showed that in three stations of Anzali, Sanandaj and Khoram Abad, the independent variable of annual rainfall does not affect the maximum daily rainfall as a dependent variable and in other stations the effect of annual precipitations is positive and significant. In the other words, increase in annual precipitation has been simultaneous with the increase in diurnal rainfalls. Moreover studying the series changes regarding the proportion of the highest diurnal precipitations to annual precipitations showed that during the statistical period except in Sanandaj station, in other stations in Iran, we cannot see any significant difference among the studied decades in terms of the proportion of highest daily to annual precipitations. So that this proportion has not changed significantly during the statistical period. Then for determining spatial pattern of the condition of the highest daily precipitations in Iran, the highest daily precipitations and their proportion to annual precipitations were classified and in this regard, classification of distribution of the proportion of highest daily to annual precipitations in Iran was done using cluster method. The results have divided Iran into 5 different regions (Reference to Figure 4) :

Region 1: includes stations of Sanandaj, Zanjan, Ardabil, Gorgan, Saqez, Qazvin, Khoy, Tabriz, Babolsar, Kermanshah, Khoram Abar, Bojnourd, Hamedan, Anzali and on the whole average of the proportion of maximum daily precipitations to annual was $8.2 \%$ in the region.

Region 2: includes stations of Tehran, Torbate Heydarieh, Arak, Ramsar, Shahre Kord, Mashhad, Orumiyeh, Semnan, Shahrood, Birjand, Sabzevar and Shiraz, the average of this proportion in this region is $11.8 \%$.

Region 3: this region includes stations of Bandar Abas, Chabahar, Bandar Lengeh, Jask and Iranshahr. The average of this proportation is $32 \%$ in this region.

Region 4: stations of Fasa, Kerman, Ahvaz, Kashan, Tabas, Esfehan and Dezfoul are in this range, the average of their proportion is $16 \%$.

Region 5: includes stations of Yazd, Zahedan, Bam, Zabol, Abadan, Abadeh and Boushehr where $23.4 \%$ of the annual precipitation happens in one day.

It is possible that this classification does not match other precipitation characteristics because this classification is merely based on the proportion of maximum diurnal to annual precipitations. Also in this regard absolute (maximum) amounts of highest daily precipitations are classified that reveals that the highest of these amounts is in the northern and southern coastal zones and then western areas that shows high humidity and rising factors in these regions and the least of these amounts is seen in the central and eastern zones that demonstrates lack of humidity.

\section{References}

Alijani, B. (2002). Climate of Iran (p. 221) (5th ed.). Iran: Payame Nour Press.

Babai, F. O. S., \& Faraj, Z. A. M. (2001). Patterns of Temporal and Spatial Changes of Precipitations in Iran. Geographical researches Journal, 62, 114-125.

Faraji, S. H. A., \& Azizi, G. (2006). Evaluation of Accuracy of Spatial Interpolation Methods. Geographical Researches Journal, 58, 1-15. (In Persian)

Fujibe, F., Yamazaki, N., Katsuyama, M., \& Kobayashi, K. (2005). The increasing trend of intense precipitation 
in japan based on four-hourly data for hundred years. SOLA, 1, 41-44. http://dx.doi.org/10.2151/sola.2005-012

Ghanbarpour, M. R., \& Talouri, A. (2003). Pattern of Temporal Showers in Synoptic Stations of the North of Iran. Journal of Research and Construction, 59, 96-103. (In Persian)

Ghanbarpour, M. R., Mahdavi. M., \& Talouri, A. (2000). The relationship between highest daily and short precipitations in Iran. Journal of Research and Construction, 49, 22-26. (In Persian)

Hajjam, S., Khoshkhal, U., \& Shamseddinvandi, R. (2008). Analysis of the trend of the changes in annual and seasonal precipitations in some elected stations in central zone of Iran using non parametric method. Geographical Research Journal, 64, 157-168. (In Persian)

Harpham, C., \& Robert, L. W. (2005). Multi-site downscaling of heavy daily precipitation occurrence and amounts. Journal of Hydrology, 312, 235-255. http://dx.doi.org/10.1016/j.jhydrol.2005.02.020

Heidari, I. ( 2002). Synoptic analysis of the highest monthly precipitations of the west of Iran in watery year of Iran 1984-1985. MA thesis. Razi University of Kermanshah. Iran. (In Persian)

Jahanbakhsh, A. S., \& Zolfaghari, H. (2000). Investigation of highest daily precipitations from western north western south of Iran. Faculty of Humanities newspaper (Tabriz), 174, 87-114.

Karl, T. R., \& Knight, R. W. (1998). Secular trend of precipitation amount, frequency, and intensity in the United states. Bulletin of the American Meteorological Society, 79(2), 231-241. http://dx.doi.org/10.1175/1520-0477(1998)079<0231:STOPAF $>2.0 . C O ; 2$

Khaleghi, Z. H., \& Marzban, D. M. (2006). Synoptic investigation of daily precipitations of more than $50 \mathrm{~mm}$ in Kohgilouyeh and Bouyer Ahmad. First Local Seminar of Exploitation. Iran. Shahrekord. Iran. Retrieved from http://www.civilica.com

Lana, X., Milles, E., \& Burgoeno, A. (1995). Daily precipitation maxima in Catalonia (north-east Spain): Expected values and their spatial distribution. International Journal of Climatology, 15(3), 344-354. http://dx.doi.org/10.1002/joc.3370150309

Lashgari, H. (1996). Synoptic pattern of heavy precipitations in western south of Iran (pp. 1-10). PhD thesis. Tarbiat Modarres University. Iran.

Massoudian, S. A. (2000). Investigation of Changes in Distribution and Frequency of the Amount of Daily Precipitations in Karun Region. Faculty of Humanities Studies and Researches, 22-23, 205-216. (In Persian)

Mofidi, A. (2004). Synoptic Climatology of red sea originate heavy precipitations in middle east. Geographical researches Journal, 75, 71-93. (In Persian)

Mohammadi, H., \& Taqavi, F. (2005). Extreme Trends of Temperature and Precipitation Coefficients in Iran. Geographical Researches journal, 53, 151-172. (In Persian)

Nastos, P. T., \& Zerefos, C. S. (2007). On extreme daily precipitation totals at Athens, Greece. Adv Geosci, 10, 59-66. http://dx.doi.org/10.5194/adgeo-10-59-2007

Nejhad, P., Katirai, P., \& Hajjam, S. (2007). Share of frequency changes and intensity of diurnal precipitation in the trend of precipitations in Iran in the period 1960-20. Earth and Space Physics Research Journal, 33, 67-83. (In Persian)

Nishiyama, K., Shinichi, E., Kenji, J., Cintia. B., Jonas, O., \& Ronny, B. (2007). Identification of typical synoptic patterns causing heavy rainfall in the rainy season in japan by a self-organizing map. Atmospheric research, 83, 185-200. http://dx.doi.org/10.1016/j.atmosres.2005.10.015

Peralta-Hernandez, A. R, Balling, R. C., \& Barba-Martinez, L. R. (2009). Comparative analysis of indices of extreme rainfall event: variation and trend from southern Mexico. Atmosfera, 22, 219-228.

Radmanesh, F., Behniya. A., \& Akhond, A. A. M. (2006). The Relationship between daily precipitations and precipitations lasting more than one day in the western south of Zagros. The first national seminar in Management of irrigation and drainage networks. Ahvaz. Iran. Retrieved from http://www.civilica.com/Paper-IDNC01-IDNC01_167.html

Rahim, Z. F. (2005). Investigation of the changes in extreme amounts of precipitation in Iran. Nivar magazine (pp. 58-59 \& 7-20).

Ramasamy, S., \& Kevin, J. H. (1998). Trends in total rainfall, heavy rain event and number of dry in Australia 1910-1990. International Journal of climatology, 10, 1141-1164. 
Razi'ie, T., \& Azizi, Gh. (2008). Study of spatial distribution of seasonal and annual precipitations in the west of Iran. Physical geography Research quarterly, 65, 93-108.

Rubinic, J., \& Ožanic, N. (2006). the Relation between Intensive Daily and Annual Precipitation Quantities at the Gorski Kotar Area (Croatia). Hrvatski meteorološki časopis, 40, 631-633. 